\title{
Commentary on "Strong adverse prognostic impact of hyperglycemic episodes during adjuvant chemoradiotherapy of glioblastoma multiforme"
}

\author{
Colin E. Champ $\cdot$ Rainer J. Klement
}

Published online: 9 December 2014

(C) Springer-Verlag Berlin Heidelberg 2014

Based on a retrospective analysis of 106 patients, Mayer et al. [1] recently described a "strong adverse prognostic impact of hyperglycemic episodes during adjuvant chemotherapy of glioblastoma multiforme" (GBM). The overall survival of patients with one or more episodes of hyperglycemia, defined as a blood glucose measurement $>10 \mathrm{mM}$, was 8.8 months compared to 16.7 months in those without hyperglycemia, and the association between hyperglycemic episodes and shorter survival remained significant in various subgroup analyses including the group with the most favorable expectations. Hyperglycemia also remained a significant predictor variable in a multivariate Cox proportional hazards model, indicating that a poor overall condition (e.g., patients requiring more glucocorticoids) cannot fully explain this relation. Indeed, the authors discussed several plausible explanations for their finding, at the same time rightfully acknowledging that their data are not able to deduce a causative role of high blood glucose per se for decreasing survival. However, given the consistency of this association not only between these data and previous studies on GBM patients, but also for a variety of other cancer sites,

Original article: Mayer A, Vaupel P, Struss H-G, Giese A, Stockinger M, Schmidberger H (2014) Strong adverse prognostic impact of hyperglycemic episodes during adjuvant chemoradiotherapy of glioblastoma multiforme. Strahlenther Onkol 190:933-938

Dr. R. J. Klement, $\operatorname{PhD}(\bowtie)$

Department of Radiotherapy and Radiation Oncology, Leopoldina Hospital Schweinfurt, Gustav-Adolf-Straße 8, 97422 Schweinfurt, Germany

e-mail: rainer_klement@gmx.de

C. E. Champ, MD

Department of Radiation Oncology,

University of Pittsburgh Cancer Institute, Pittsburg, PA, USA one has to logically ask whether it would not be clinically relevant to attempt to keep blood glucose within the normal range. While withdrawing patients from glucocorticoids is no realistic option to achieve this goal, dietary manipulation in our opinion is. Although Mayer et al. correctly state that their data provide no evidence for the usefulness of diets aimed at avoiding hyperglycemia, along the same lines their data do not justify their warning against such diets which they spell out in their conclusions. One of us (CC) has recently shown that very low carbohydrate ketogenic diets (VLCKDs) are able to significantly reduce blood glucose levels in GBM patients, even under high doses of glucocorticoids [2], a result that should be considered positive in light of the findings of Mayer et al. It is therefore not clear to us why the authors warn against the use of VLCKDs, especially since such diets have shown great potential for the treatment of GBM [3-6]. The fear that ketone bodies might fuel GBM growth is not supported by any data we are aware of - the study of Bonuccelli et al. [7] cited by the authors was performed on breast cancer cells genetically modified to overexpress rate-limiting enzymes of ketone body utilization, a model that hardly resembles the characteristics of normal tumor cells, let alone GBM cells. Quite contrary, human GBM tumors have been shown to possess a dysfunctional oxidative phosphorylation system that would not allow efficient utilization of ketone bodies for energy production [8]. Moreover ketone body utilization would not be possible in hypoxic tumor areas. In addition, a large fraction of GBM tumors possess low activity of key enzymes needed to process ketone bodies to acetyl-CoA [9].

We have recently summarized the large body of evidence showing how VLCKDs activate the same molecular mechanisms that are targeted individually by anticancer drugs and may act synergistically with radiation- and chemotherapy [10]. Therefore, and due to the fact that such diets consti- 
tute the treatment of choice for seizure reduction in drugresistant epilepsy [11], we would more caution against not considering them as supportive treatment options for GBM patients. As no serious side effects of VLCKDs have yet been reported even in advanced cancer patients [12, 13], the burden of proving any clinically harmful effect rests upon those who warn against their usage.

\section{Compliance with ethical guidelines}

Conflict of interest R.J. Klement and C.E. Champ state that there are no conflicts of interest.

\section{References}

1. Mayer A, Vaupel P, Struss H-G, Giese A, Stockinger M, Schmidberger H (2014) Strong adverse prognostic impact of hyperglycemic episodes during adjuvant chemoradiotherapy of glioblastoma multiforme. Strahlenther Onkol 190:933-938

2. Champ CE, Palmer JD, Volek JS, Werner-Wasik M, Andrews DW, Evans JJ et al (2014) Targeting metabolism with a ketogenic diet during the treatment of glioblastoma multiforme. J Neurooncol 117(1):125-131

3. Seyfried TN, Kiebish M, Mukherjee P, Marsh J (2008) Targeting energy metabolism in brain cancer with calorically restricted ketogenic diets. Epilepsia 49:114-116

4. Zuccoli G, Marcello N, Pisanello A, Servadei F, Vaccaro S, Mukherjee $\mathrm{P}$ et al (2010) Metabolic management of glioblastoma multiforme using standard therapy together with a restricted ketogenic diet: case report. Nutr Metab 7:33
5. Seyfried TN, Flores R, Poff AM, D'Agostino DP, Mukherjee P (2014) Metabolic therapy: a new paradigm for managing malignant brain cancer. Cancer Lett. pii: S0304-3835(14)00352-8. doi:10.1016/j.canlet.2014.07.015 (Epub ahead of print)

6. Woolf EC, Scheck AC (2014) The ketogenic diet for the treatment of malignant glioma. J Lipid of Res (Epub ahead print)

7. Bonuccelli G, Tsirigos A, Whitaker-Menezes D, Pavlides S, Pestell RG, Chiavarina B et al (2010) Ketones and lactate "fuel" tumor growth and metastasis: evidence that epithelial cancer cells use oxidative mitochondrial metabolism. Cell Cycle 9:3506-3514

8. Feichtinger RG, Weis S, Mayr JA, Zimmermann F, Geilberger $\mathrm{R}$, Sperl W et al (2014) Alterations of oxidative phosphorylation complexes in astrocytomas. Glia 62:514-525

9. Chang HT, Olson LK, Schwartz KA (2013) Ketolytic and glycolytic enzymatic expression profiles in malignant gliomas: implication for ketogenic diet therapy. Nutr Metab 10:47

10. Klement RJ, Champ CE (2014) Calories, carbohydrates, and cancer therapy with radiation: exploiting the five R's through dietary manipulation. Cancer Metastasis Rev 33:217-229

11. Paoli A, Rubini A, Volek JS, Grimaldi KA (2013) Beyond weight loss: a review of the therapeutic uses of very-low-carbohydrate (ketogenic) diets. Eur J Clin Nutr 67:789-796

12. Schmidt M, Pfetzer N, Schwab M, Strauss I, Kämmerer U (2011) Effects of a ketogenic diet on the quality of life in 16 patients with advanced cancer: a pilot trial. Nutr Metab 8:54

13. Rieger J, Bähr O, Maurer GD, Hattingen E, Franz K, Brucker D et al (2014) ERGO: a pilot study of ketogenic diet in recurrent glioblastoma. Int J Oncol 44:1843-1852 